\title{
ION PERMEATION STUDY ON CELLULOSE ACETATE/ CHITOSAN MEMBRANE WITH MULTIVALENT AQUEOUS ELECTROLYTE SOLUTION
}

\author{
A. K. Tiwari ${ }^{1} *$ and Satya Nath ${ }^{2}$ \\ Department of chemistry D.D.U. Gorakhpur University, Gorakhpur-273009(U.P.) India \\ *E-mail:dr_aktiwari@rediffmail.com
}

\begin{abstract}
The present study CA/chitosan blend membrane was prepared by solvent vaporization method. The morphology of membrane was studied using Scanning Electron Microscopy (SEM) and the thermal stability using Thermo Gravimetric Analysis (TGA); and the physicochemical properties such as water content, kinetic of membrane flux, permeability and flow were investigated. Parameters on which membrane selectivity depends, are also discussed. It has also been explored the effect of electrolyte solution on ion transport properties of cellulose acetate /chitosan membrane under a concentration gradient. Water uptake in the absence and presence of electrolyte were carried out. The thermal stability of Cellulose acetate /Chitosan blends membrane to provide information regarding weight loss of the prepared membrane represent some significant steps i.e. water loss from membrane phase, followed by degradation process. First weight loss occurred at 80 to $130{ }^{\circ} \mathrm{C}$ which conform evaporation of residual water from the membrane. The second degradation stage was noticed around $360.36{ }^{\circ} \mathrm{C}$, which are due to amino and hydroxyl groups. The work has been done with the object to investigate the transport properties of cellulose acetate /chitosan synthetic membrane, conducted under a concentration gradient .More ever, the water uptake and conductance experiment were carried out to investigate the effect of those electrolyte solutions. As time increases, the density of membrane functional groups increases and approaches to narrow proximity to each other. Membrane water retention capacity varies electrolyte to electrolyte. In present case it is $83.6 \%$ for $0.01 \mathrm{M}, \mathrm{NaCl} ; 50.9 \%$ for $0.01 \mathrm{M}, \mathrm{MgCl}_{2}$ and $44.0 \%$ for $0.01 \mathrm{M} \mathrm{BaCl}_{2}$.
\end{abstract}

Keywords: Cellulose acetate, chitosan, water content, rate constant and flux.

(C) RASĀYAN. All rights reserved

\section{INTRODUCTION}

The attempts on membrane development have covered technique to a new family of future product and utilization ${ }^{1,2}$. Good separation of membrane needs various new technique which has been applied to upgrade $\mathrm{it}^{3,4}$. Polymer mixing process has been found to be a productive way to control the imperfection of the polymeric membrane, because mixing at the molecular level due to chemical interaction may generate the possibilities of chemical bond formation ${ }^{5}$. Adsorptive membranes have many advantages, including high separation rates, high productivity, and large permeating flux ${ }^{6}$. Cellulose acetate and chitosan are considerably adaptable and versatile biomaterial ${ }^{7,8}$. The deacetylated chitin derivative, chitosan is a more significant bioactive polymer. It has many reactive amino groups which provide the opportunity for chemical moderation. Cellulose acetate /chitosan blend membrane was synthesized by the solvent vaporization method. The cellulose acetate/chitosan membrane possesses more hydrophilicity than cellulose acetate membrane, because of the free amino group present in chitosan membrane. Chitin is a polysaccharide structurally similar to cellulose. It is mostly found in the shell of crustacean and the exoskeletons of arthropods. Like cellulose, chitin has $\beta-1,4-$ glycosidic linkages. It differs from cellulose through it has an $\mathrm{N}$-acetyl amino group instead of an $-\mathrm{OH}$ group at the $\mathrm{C}_{2}$ position. Similarly the principal derivative of chitin, chitosan is a linear polymer of $(1 \rightarrow 4)$-linked -2 amino-2-deoxy- $\beta$-D-glucopyranose) and easily obtained by $N$ deacetylation ${ }^{9}$.Chitosan, one of the natural various functional polymers due to its especial and

Rasayan J. Chem., 12(1), 73-84(2019)

http://dx.doi.org/10.31788/RJC.2019.1213093

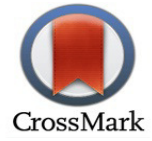


resourceful biological properties, is considered a useful compound in medical and pharmaceutical technology.

The stability of chitosan is of the great problem of the practical relevance. Thus, it has become a great challenge to establish durability. For improved stability of chitosan, the formulation can be achieved by controlling the environmental factor. The stability of chitosan can be improved by adding the cellulose acetate polymer ${ }^{10}$.

The conductivity of a solution depends on the salt concentration. While incorporating the polymer with the salt resulting change its conductivity. As the conductivity increases, the number of complexation site of the polymer also increases. The mixture of two polymers has been facilitating to grow more complexation site which provides room for ionic migration ${ }^{11}$.

Permeation of solute through cellulose acetate /chitosan membrane is remained yet the significant point of attention to enhance its practical applicabilities i.e. the removal of dissolved impurities in water by membrane process ${ }^{12}$. Membrane activity can be modified at a desired level by co-mixing of materials at the beginning step of membrane preparation ${ }^{13,14}$. With the help of this method, varying degree of hydrophilicity in the membrane property can be achieved which may be helpful to minimize the fouling characteristic. There is one effective way to prepare blend membrane for the sake of better performance.

Cellulose acetate/chitosan membrane was prepared by solvent vaporization process. Membrane morphology was studied by SEM .TGA analysis gives the information about thermal stability of the membrane. Kinetic of ionic flow, permeability and flux were determined on the basis of water content and conductance measurement.

\section{Chemical and Membrane Material}

\section{EXPERIMENTAL}

Cellulose acetate was purchased from BDH chemical, Ltd Pool England. Chitosan and acetone were purchased from Qualigens Fine Chemical, India. Sodium Chloride and Barium Chloride dihydrate were purchased s.d fine Chemical Limited. Magnesium Chloride hexahydrate was purchased from Merck Specialities.

\section{Preparation of Cellulose Acetate /Chitosan Membrane}

$1.5 \mathrm{gm}$ cellulose acetate and $0.5 \mathrm{gm}$ chitosan were mixed in $20 \mathrm{~mL}$ of acetone. The whole mixture was stirred 2-4 hours with the help of magnetic stirrer until the slurry was obtained. It was spread on a clean dried glass plate. The glass plate containing membrane was kept in an oven at $60{ }^{\circ} \mathrm{C}$ for about an hour for solvent evaporation. The plate was then submerged in distilled water to detach the membrane. The membrane was kept compressed between filter paper.

\section{Membrane Characterization \\ Scanning Electron Microscopy (SEM)}

The membrane surface morphology is characterized by Scanning Electron Microscope shown in Fig.-7.

\section{Thermo Gravimetric Analysis (TGA)}

The weight loss of membrane is carried out by TGA instrument at the heating rate $20{ }^{\circ} \mathrm{C} /$ minute. Approximately $3.67 \mathrm{mg}$ of membrane heated $40{ }^{\circ} \mathrm{C}$ to $74{ }^{\circ} \mathrm{C}$ is shown in Fig.-8.

\section{Determination of Water Content of the Membrane}

From the prepared cellulose acetate/chitosan, one piece of area $3 \times 3 \mathrm{~cm}^{2}$ was taken. The membrane of the known area was weighed first and then submerged in $25 \mathrm{~mL}$ distilled water for different time intervals. After the completion of the work, the membrane was removed from the water and pressed between the fold of filter paper. The weight of membrane was taken in wet condition. Water content was calculated by using the following relation:

$$
\mathrm{Q}_{\mathrm{w}}=\left\{\frac{\text { wet weight of membrane-dry weight of membrane }}{\text { dry weight of membrane }}\right\}
$$




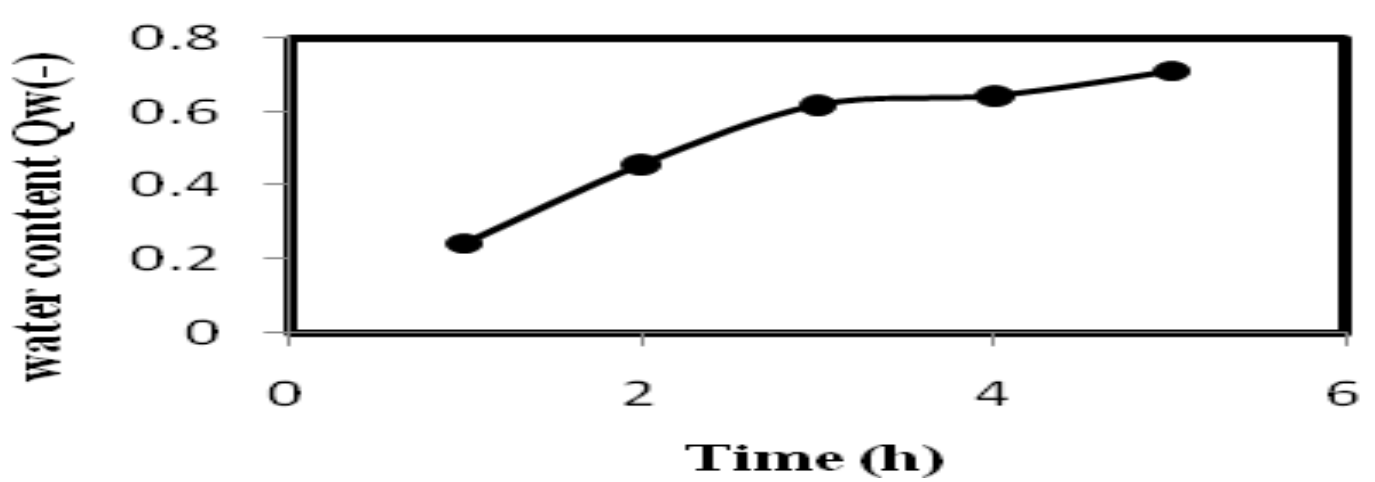

Fig.-1: Dependence of Water Content with respect to Time

Dependence of Water Content of the Membrane with respect to the Concentration of $\mathrm{NaCl}, \mathrm{MgCl}_{2}$ and $\mathrm{BaCl}_{2}$ Solution

Cellulose acetate / Chitosan membrane of area $3 \times 3 \mathrm{~cm}^{2}$ was immersed in different concentration of $\mathrm{NaCl}$, $\mathrm{MgCl}_{2}$ and $\mathrm{BaCl}_{2}$ solution for an hour. Water content was determined for every concentration shown in Fig.-2.

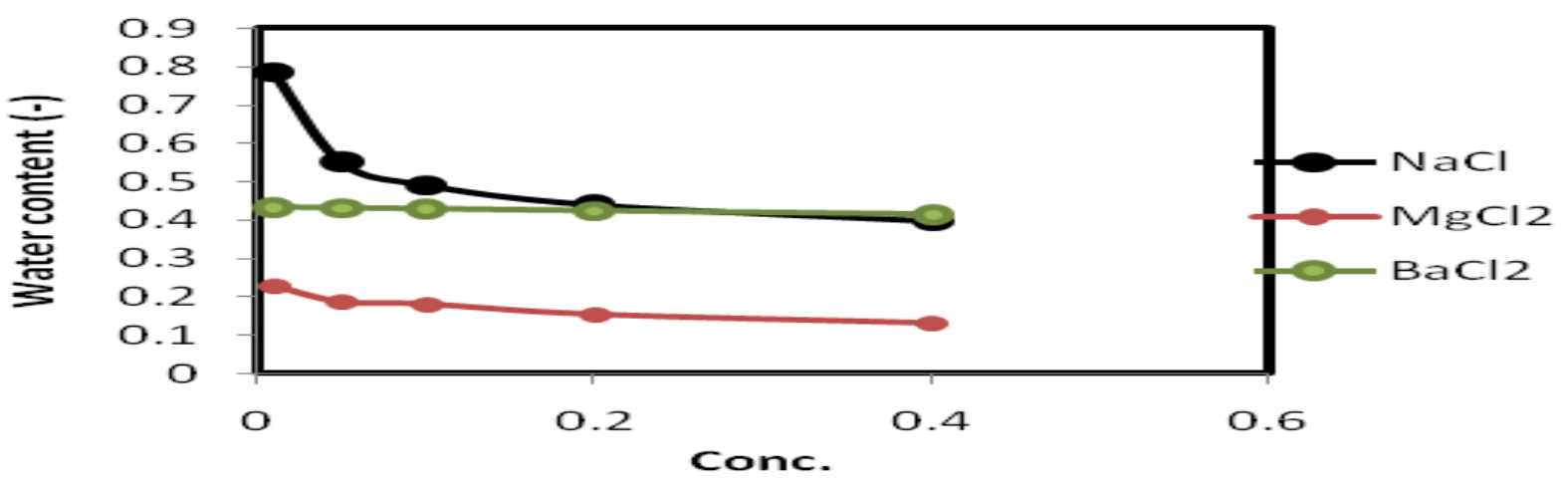

Fig.-2: Dependence of Membrane Water Content with respect to Conc. of $\mathrm{NaCl}, \mathrm{MgCl}_{2}$ and $\mathrm{BaCl}_{2}$ Solution.

Dependence of Membrane Water Content with respect to Time in Different Concentration of $\mathrm{NaCl}$ Solution

Cellulose acetate / chitosan membrane of area $3 \times 3 \mathrm{~cm}^{2}$ was immersed in varying concentration of $\mathrm{NaCl}$ for $1 \mathrm{hr}, 2 \mathrm{hr}, 3 \mathrm{hr}, 4 \mathrm{hr}$ and $5 \mathrm{hr}$ respectively. The variation in water contents was shown in Fig.-3.

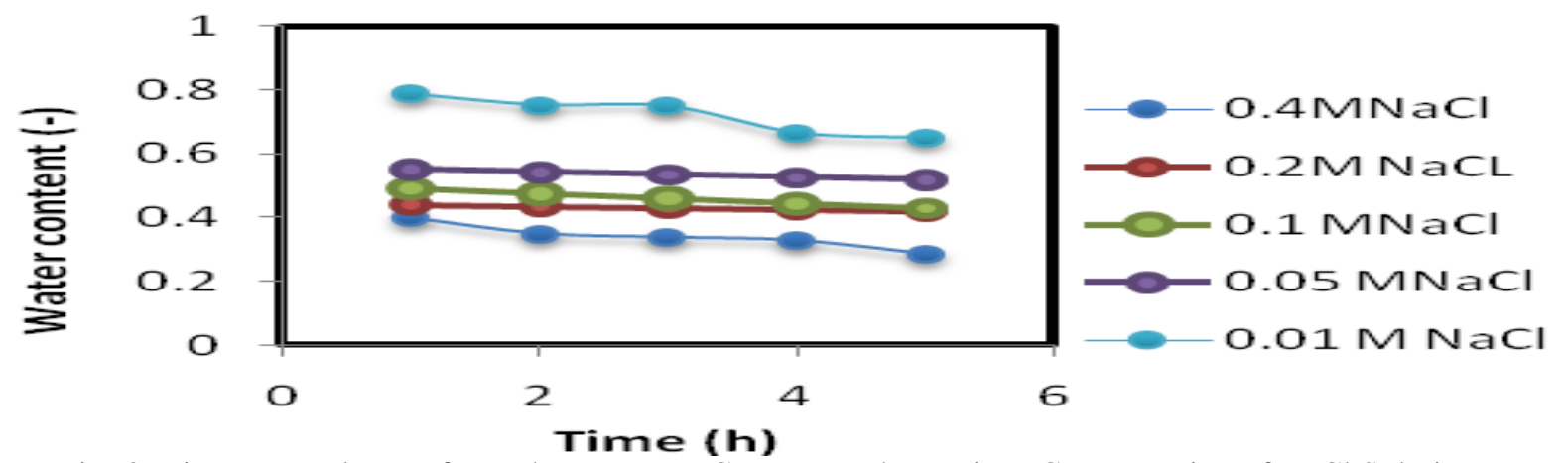

Fig.-3: Time Dependence of Membrane Water Content on the Various Concentration of $\mathrm{NaCl}$ Solution.

Dependence of Membrane Water Content with Respect to Time in Different Conc. in $\mathbf{M g C l}_{2}$ Solution

Cellulose acetate/chitosan membrane of area $3 \times 3 \mathrm{~cm}^{2}$ was immersed in different concentration of $\mathrm{MgCl}_{2}$ solution for $1 \mathrm{hr}, 2 \mathrm{hr} 3 \mathrm{hr}, 4 \mathrm{hr}$ and $5 \mathrm{hr}$ respectively. The variations in water content are shown in Fig.-4. 
RASĀYAN J. Chem.

Vol. 12 | No. 1 |73 - 84| January - March | 2019

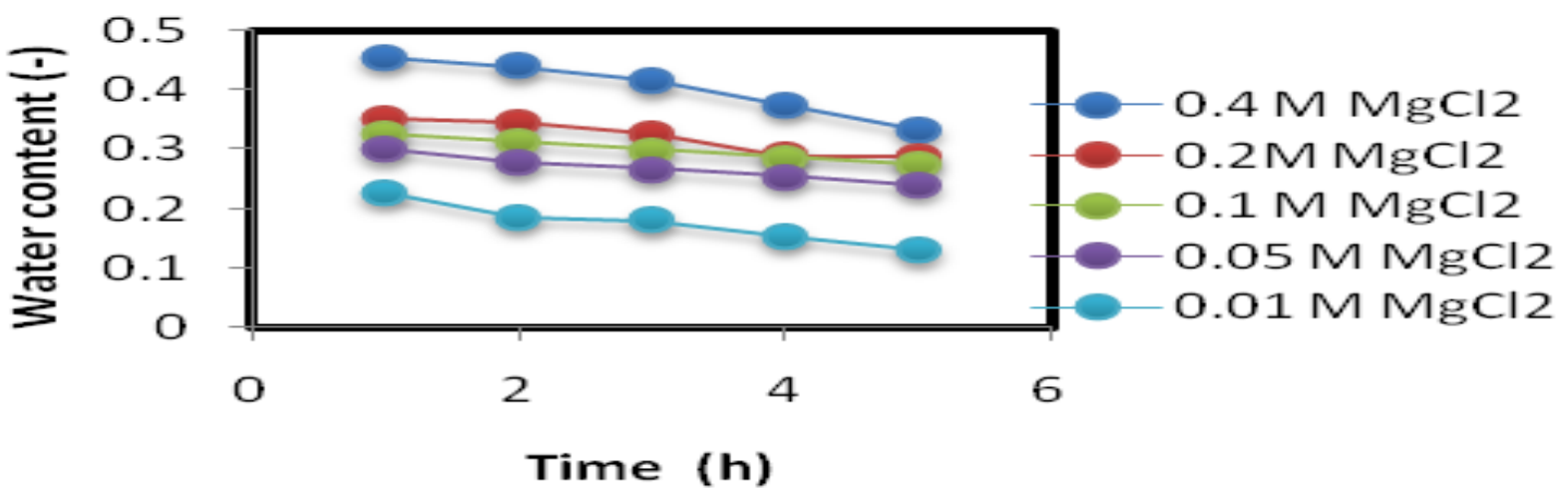

Fig.-4: Time Dependence of Membrane Water Content with Various Conc. of $\mathrm{MgCl}_{2}$ Solution.

Dependence of Membrane Water Content with Respect to Time in Different Conc. in $\mathrm{BaCl}_{2}$ Solution

Cellulose acetate / chitosan membrane of size $3 \times 3 \mathrm{~cm}^{2}$ was immersed in different concentration of $\mathrm{BaCl}_{2}$ solution for $1 \mathrm{hr}, 2 \mathrm{hr} 3 \mathrm{hr}$, $4 \mathrm{hr}$ and $5 \mathrm{hr}$ respectively. The variations in water content are shown in Fig.-5.

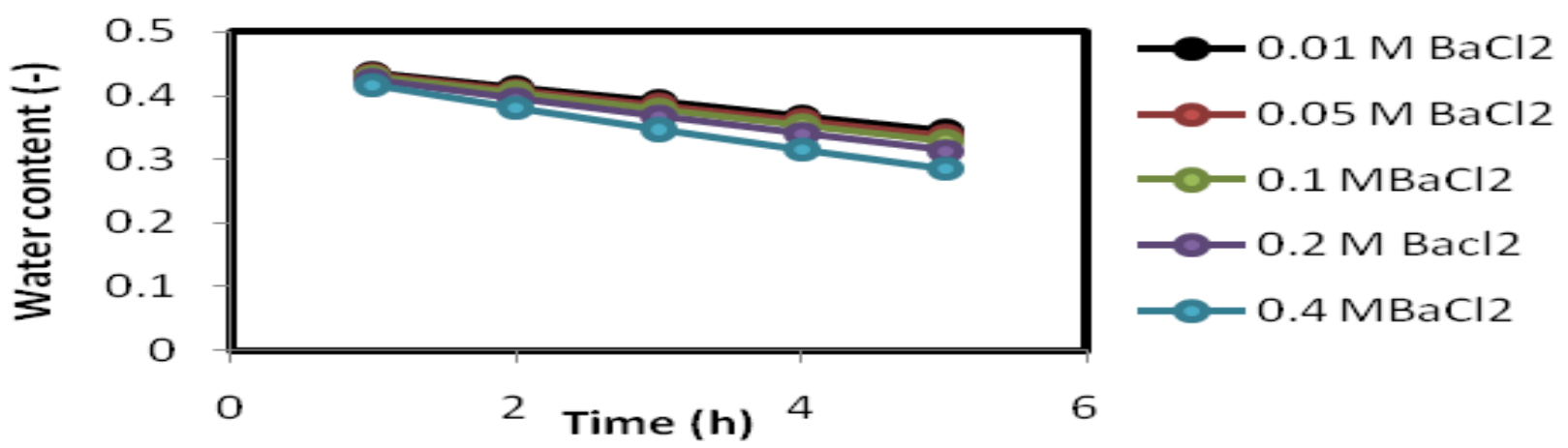

Fig.-5: Time Dependence of Membrane Water Content with Various Conc. of $\mathrm{BaCl}_{2}$ Solution.

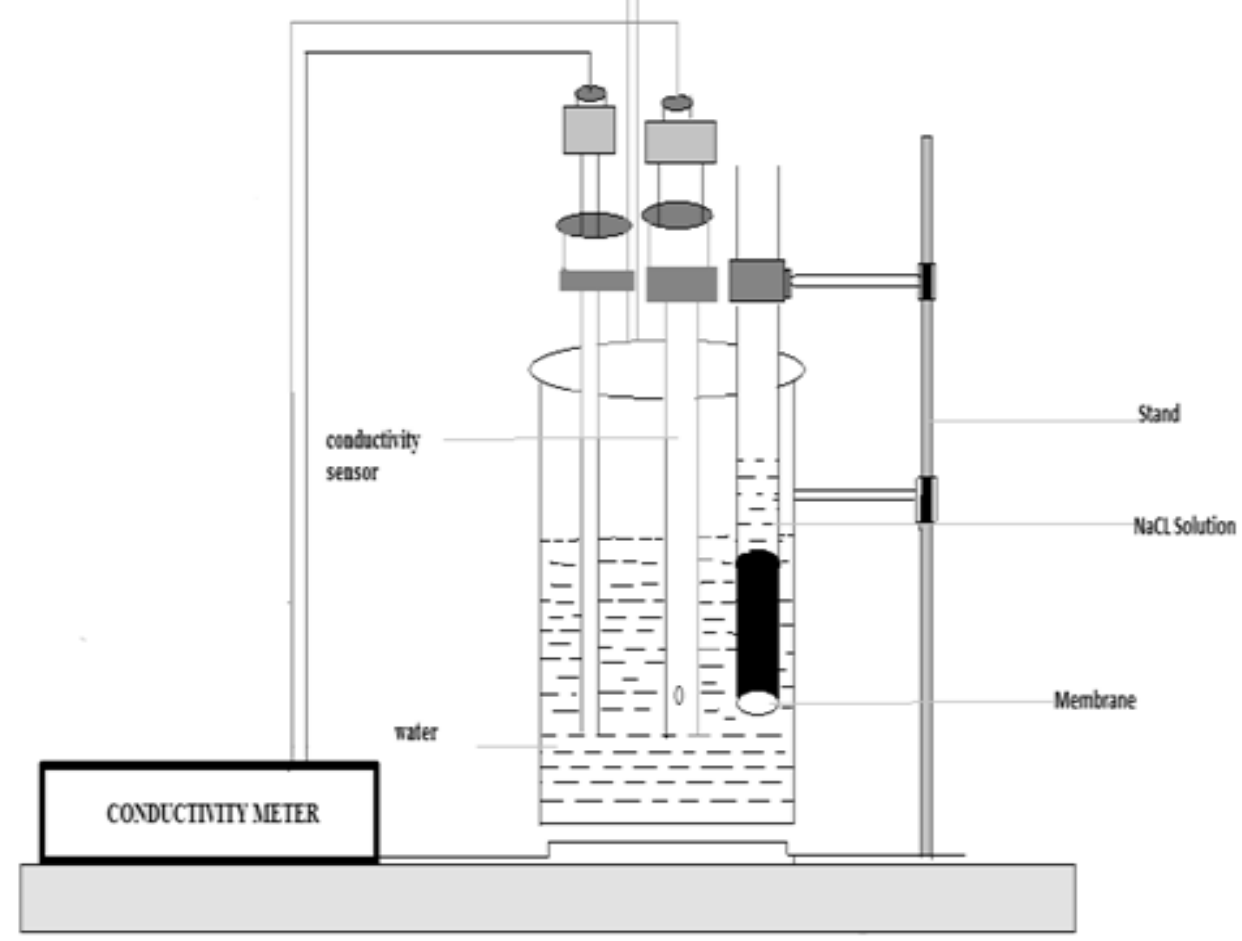

Fig.-6: Schematic Diagram of Experimental Setup 
RASĀYAN J. Chem.

Vol. 12 | No. 1 |73 - 84| January - March | 2019

\section{Conductance Measurement through the Membrane}

A piece of the membrane of area $1 \mathrm{~cm}^{2}$ was fixed in a glass tube and equilibrated with $1 \mathrm{M}$ of aqueous solutions of sodium chloride, barium chloride and magnesium chloride to change it to the appropriate ionic structure. Then it was equilibrated with an experimental solution. Before starting the experiment, the solution was renewed. The conductance of receiving phase solution was measured with the help of conductivity meter. Dependence of conductance of solution through a membrane with a time of various concentrations of $\mathrm{NaCl}, \mathrm{MgCl}_{2}$, and $\mathrm{BaCl}_{2}$ under various concentration gradients was observed and shown in the respective figure.

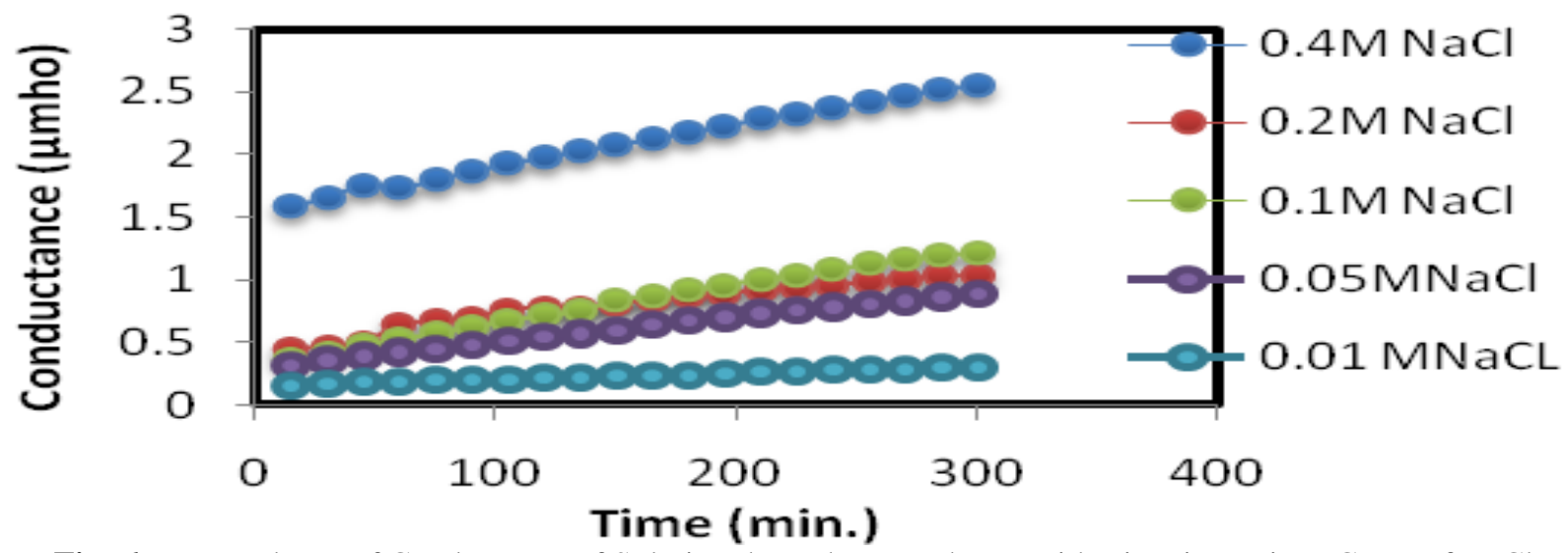

Fig.-6a: Dependence of Conductance of Solution through a Membrane with Time in Various Conc. of $\mathrm{NaCl}$

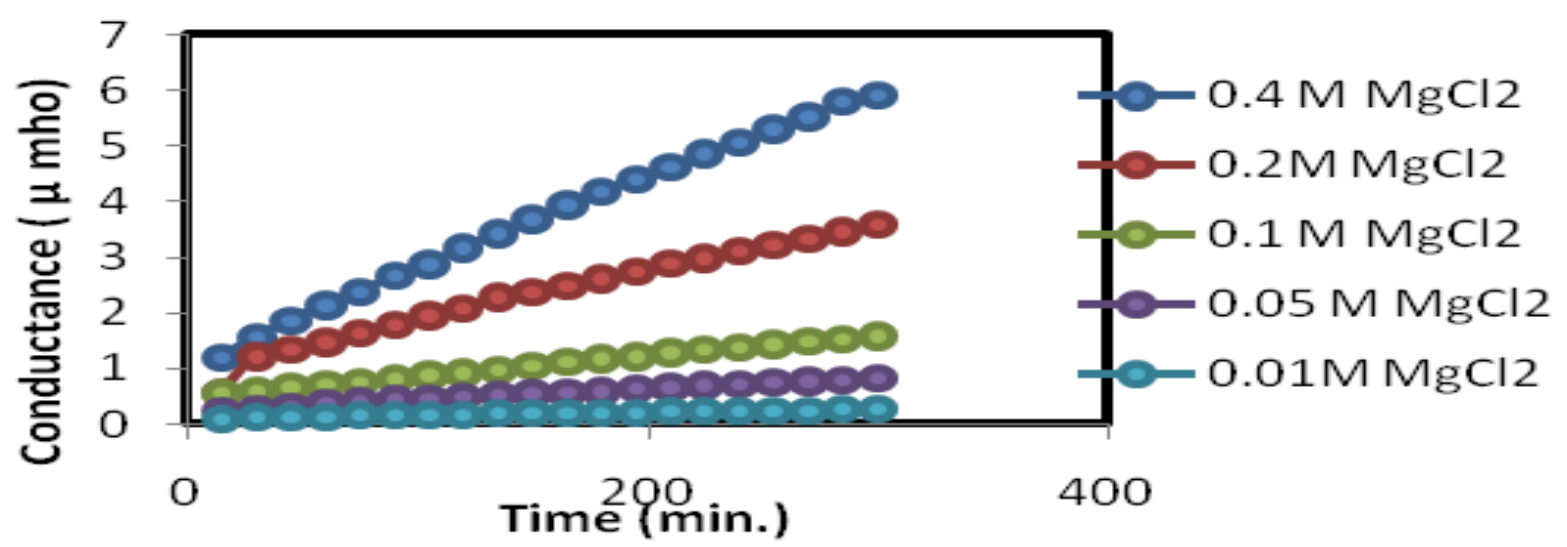

Fig.-6b: Dependence of Conductance of Solution through a Membrane with Time in Various Conc. of $\mathrm{MgCl}_{2}$

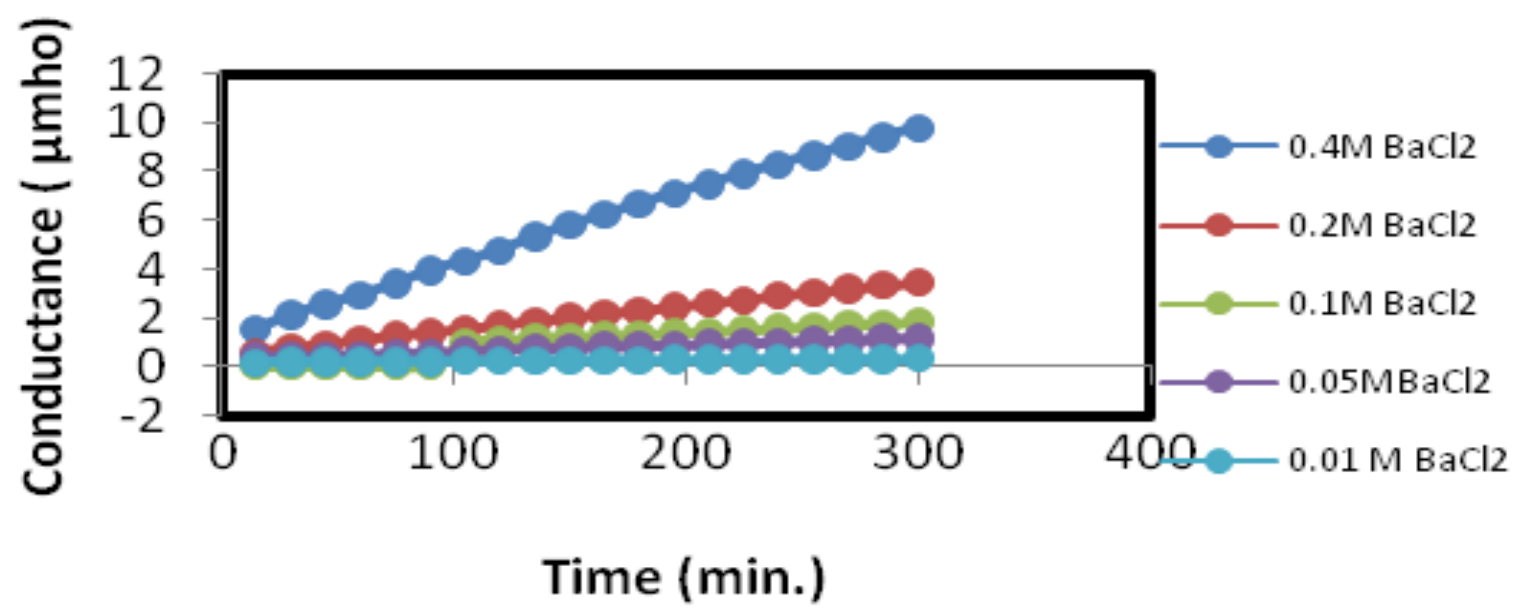

Fig.-6c: Dependence of Conductance of Solution through a Membrane with Time in Various Conc. of $\mathrm{BaCl}_{2}$ 


\section{Morphology of Cellulose Acetate/ Chitosan Membrane \\ RESULTS AND DISCUSSION}

The surface of the cellulose acetate/chitosan membrane was studied by SEM. The images of SEM can be used to determine the structures of membrane morphology .The corresponding images are shown in Fig.7. All images were showed the homogeneous structure and well-arranged network. The surface of the membrane is smooth and dense which indicates good mixing between cellulose acetate and chitosan.

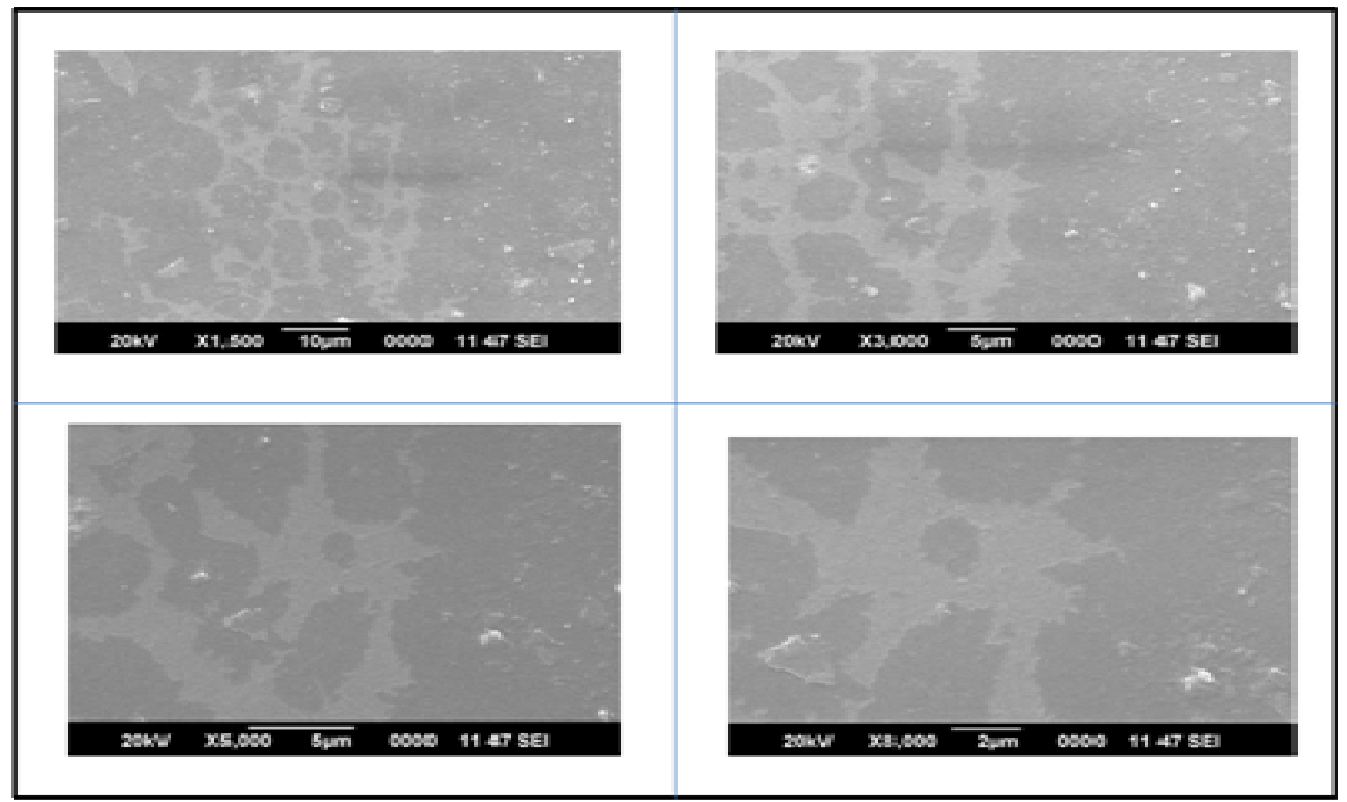

\section{TGA Analysis}

Fig.-7: SEM Images of Cellulose Acetate/Chitosan Blend Membrane

The thermal stability of cellulose acetate/chitosan blend membrane was measured on a TGA analysis and result is shown in Fig.-8a, 8b, 8c and proposed structure of the composite system of cellulose acetate/chitosan are shown in Fig.-8d.The weight loss of the prepared membrane has some important step i.e. water loss from the membrane, followed by degradation. In the first step weight loss occurred around $80{ }^{\circ} \mathrm{C}$ to $135{ }^{\circ} \mathrm{C}$, which proves the evaporation of water from the membrane. In the second stage amino and hydroxyl group loss, finally, weight loss observed at $360.36{ }^{\circ} \mathrm{C}$. The maximum degradation rates were observed at $360.36{ }^{\circ} \mathrm{C}$ due to decomposition of cellulose acetate /chitosan membrane. Initially the rate of degradation $-0.314 \mathrm{mg} / \mathrm{min}$. at temp $312.87{ }^{\circ} \mathrm{C}$ and maximum degradation rate $-1.067 \mathrm{mg} / \mathrm{min}$. at $360.36{ }^{\circ} \mathrm{C}$. In cellulose acetate /chitosan membrane cellulose acetate and chitosan membrane are combined through hydrogen bonding .In this membrane free $-\mathrm{OH}$ and $-\mathrm{NH}_{2}$ groups are present which make the anionic character of membrane responsible for cation selectivity. The free $-\mathrm{OH}$ and $-\mathrm{NH}_{2}$ group also responsible for chelating to the cation.

\section{The Water Content of the Membrane}

Water permeability and diffusion phenomena depend on the water content of the membrane. The membrane having higher water content shows higher permeability of water. Water content $\left(\mathrm{Q}_{\mathrm{w}}\right)$ was calculated using the relation-

$$
\mathbf{Q}_{\mathbf{w}}=\frac{\mathbf{W} \text { wet }-\mathbf{W d r y}}{\mathbf{w d r y}}
$$

The water content of composite cellulose acetate /chitosan membrane increases with time shown in Fig.4. After some time water content becomes invariant because of all the voids of the membrane filled with water. It shows that the highest water uptake capacity of the membrane is $71 \%$. It also shows that the membrane is hydrophilic in nature. In $\mathrm{NaCl}, \mathrm{MgCl}_{2}$ and $\mathrm{BaCl}_{2}$ solution water content decreases with time 
RASĀYAN J. Chem.

Vol. 12 | No. 1 |73 - 84| January - March | 2019

and concentration. The water uptake of the membrane is affected by the external electrolyte concentration ${ }^{15}$.
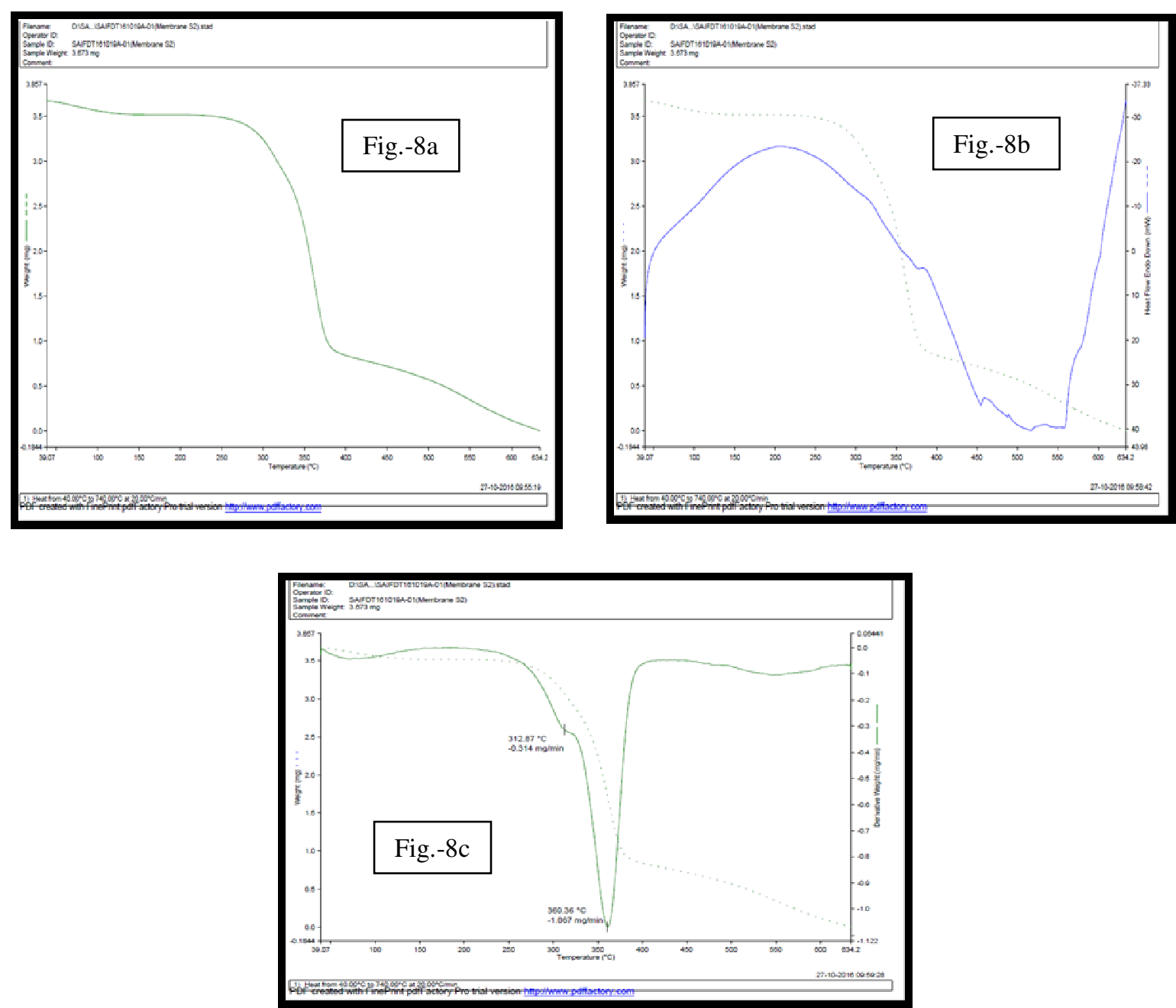

Fig.-8a, b and c

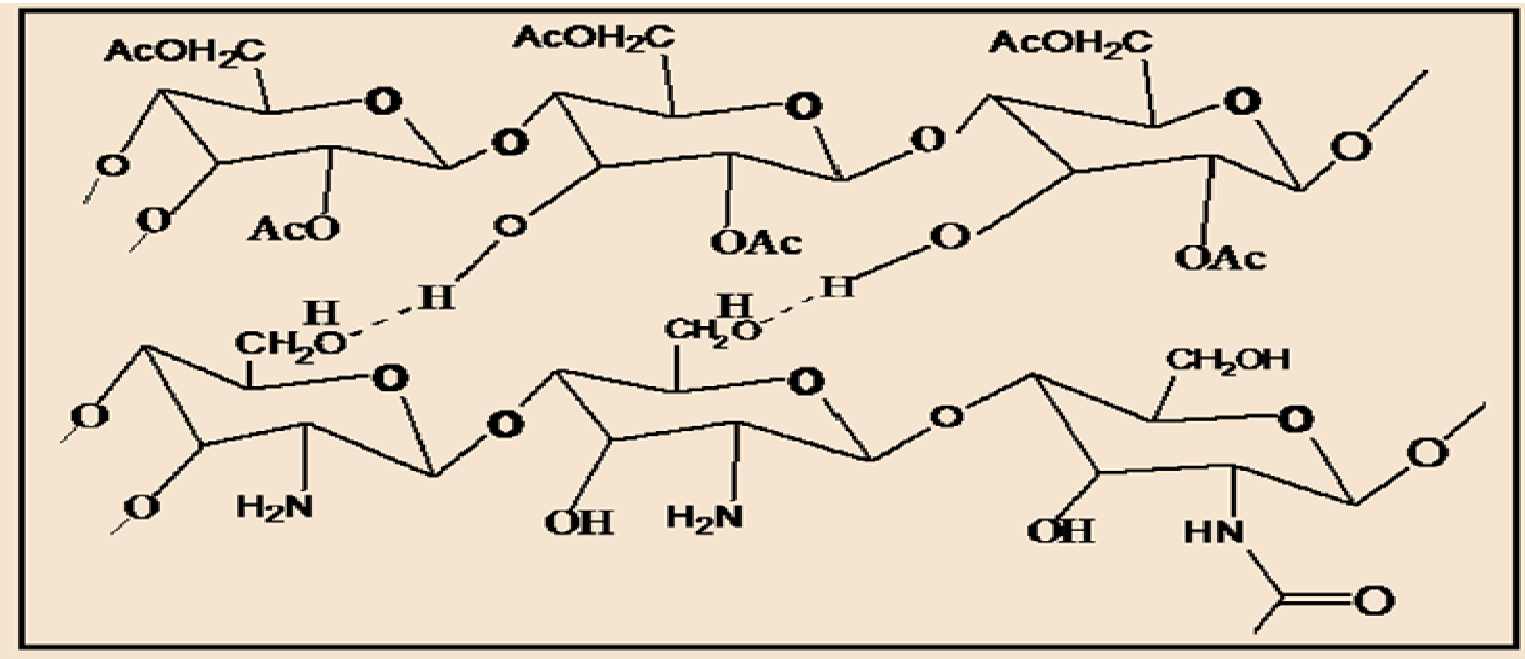

Fig.-8d: Showing the Combination of Cellulose Acetate and Chitosan through Hydrogen Bonding. 
Rate constant of water was expressed as:

$$
\frac{\mathrm{dQw}}{\mathrm{dt}}=\mathrm{k} \text { [space available in the membrane] }
$$

Rate constant was estimated by using the relation:

$$
-\mathrm{kt}=\ln \frac{(\mathrm{Q} w \max -\mathrm{Qw})}{\mathrm{Q} w \max }
$$

In solutions of $\mathrm{NaCl}, \mathrm{MgCl}_{2}$ and $\mathrm{BaCl}_{2}$ rate constant high in initial state but when time increased rate constant decreases and become constant (Fig.-9).
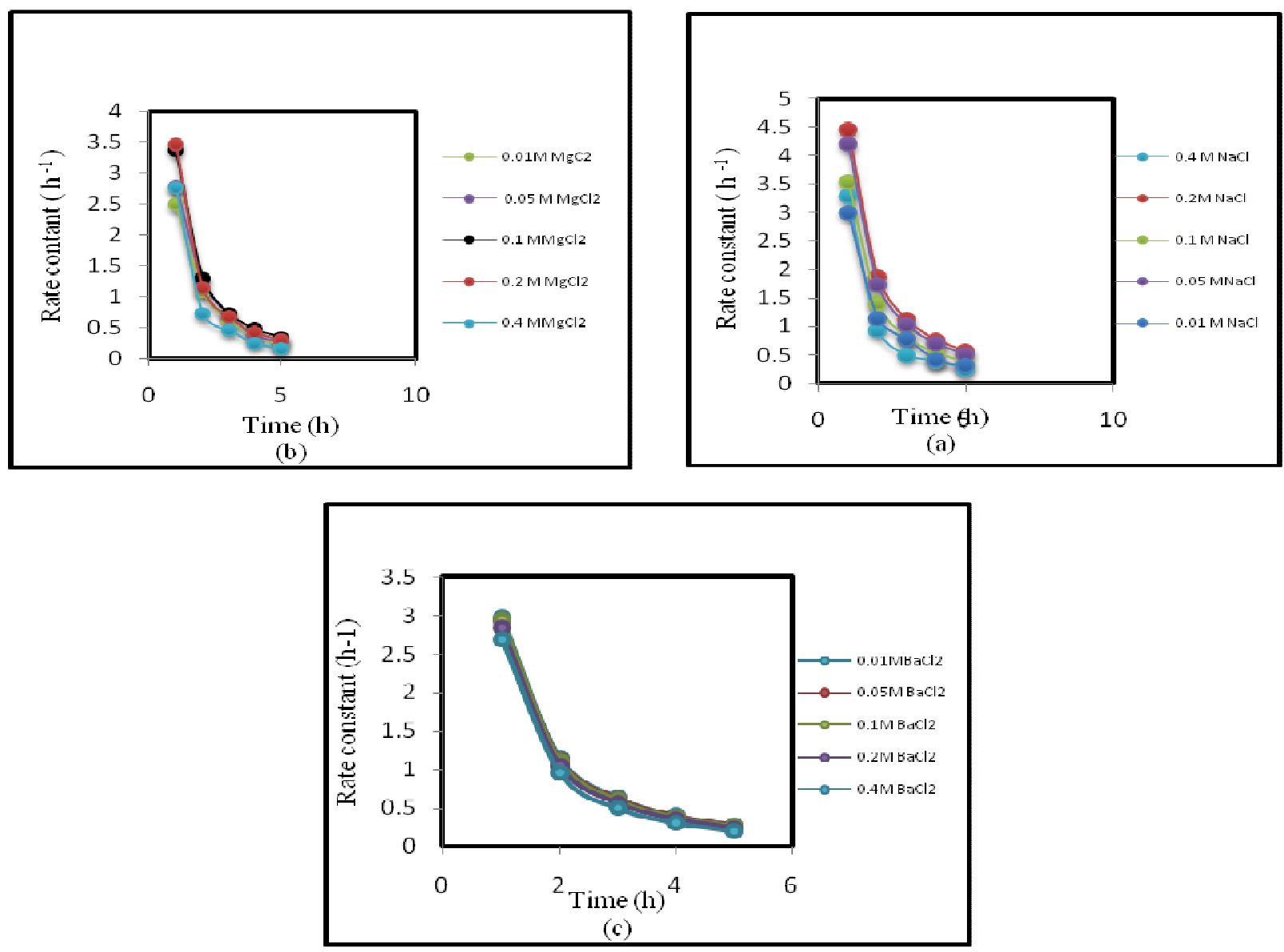

Fig.-9: Rate Constant of Water Uptake in the Membrane with (a) $\mathrm{NaCl}$,(b) $\mathrm{MgCl}_{2}$ and (c) $\mathrm{BaCl}_{2} \mathrm{Aqueous}$ Solutions

\section{Permeability Measurement}

of Various Concentrations

Permeability is typically expressed as volume or mass per unit membrane area per unit time. Water Permeability is the quantity of water (Q) moving through a cross-sectional area (A) per unit of time. This is calculated using the following equation

$$
\text { Permeability }=\frac{Q}{A \times t}
$$

Unit of permeability of the membrane is $\mathrm{cm} / \mathrm{sec}$. Where $\mathrm{Q}$ is the amount of absorbed water, $\mathrm{t}$ is the time interval and $\mathrm{A}$ is the membrane area $\left(\mathrm{m}^{2}\right)$. The flux of cellulose acetate /chitosan membrane decreased with time. Which are shown in Fig.-10.

\section{Flow, Permeability and Flux Measurement through Conductance}

The conductance of solution through the membrane increases with the increase of time, which shows in Fig.-6a, b, and c. It also shows that ions of $\mathrm{NaCl}, \mathrm{MgCl}_{2}$ and $\mathrm{BaCl}_{2}$ are transported through the membrane under the influence of concentration gradient. Following parameters are calculated: 
FLOW- Membrane flow is the rate of volume transport through the membrane pores.

Flow is calculated by the following relation-

$$
\mathrm{F}=\left(\frac{\mathrm{V}}{\mathrm{t}}\right) \ln \left[\frac{\text { Final conductance }}{\text { Initial conductance }}\right]
$$

Where $\mathrm{V}=$ Volume of the solution used for observation, $\mathrm{t}=$ Time in second

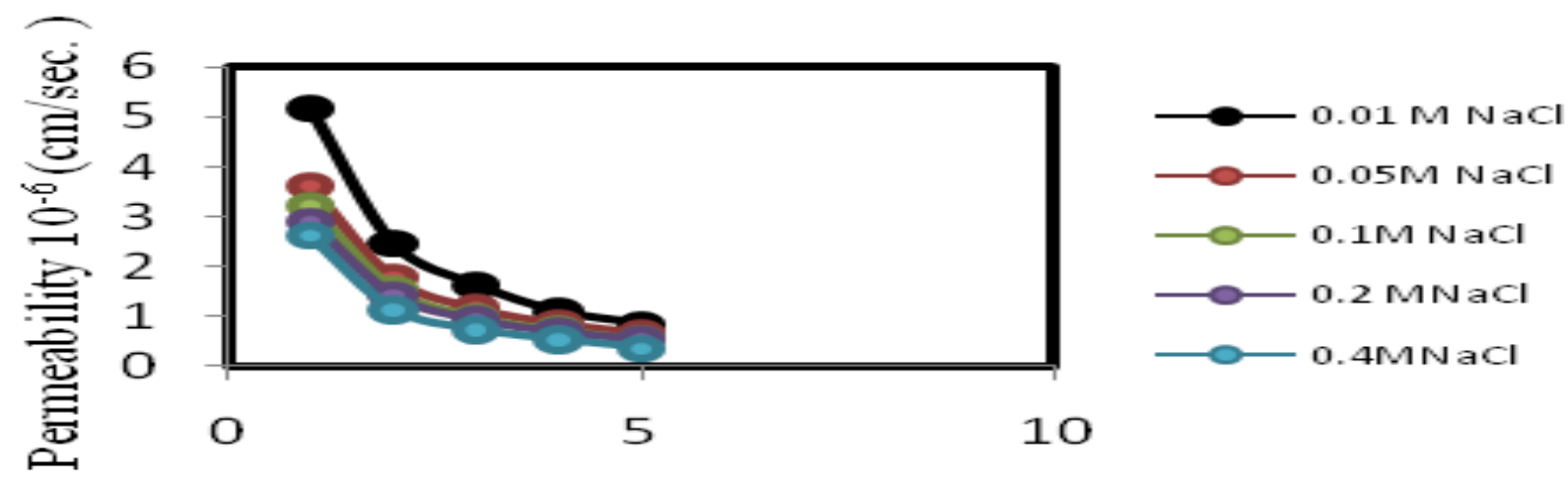

Time(h)

Fig.-10a: Dependence of Permeability in Cellulose Acetate/Chitosan Membrane with Time in Various Conc. of $\mathrm{NaCl}$ Solution.

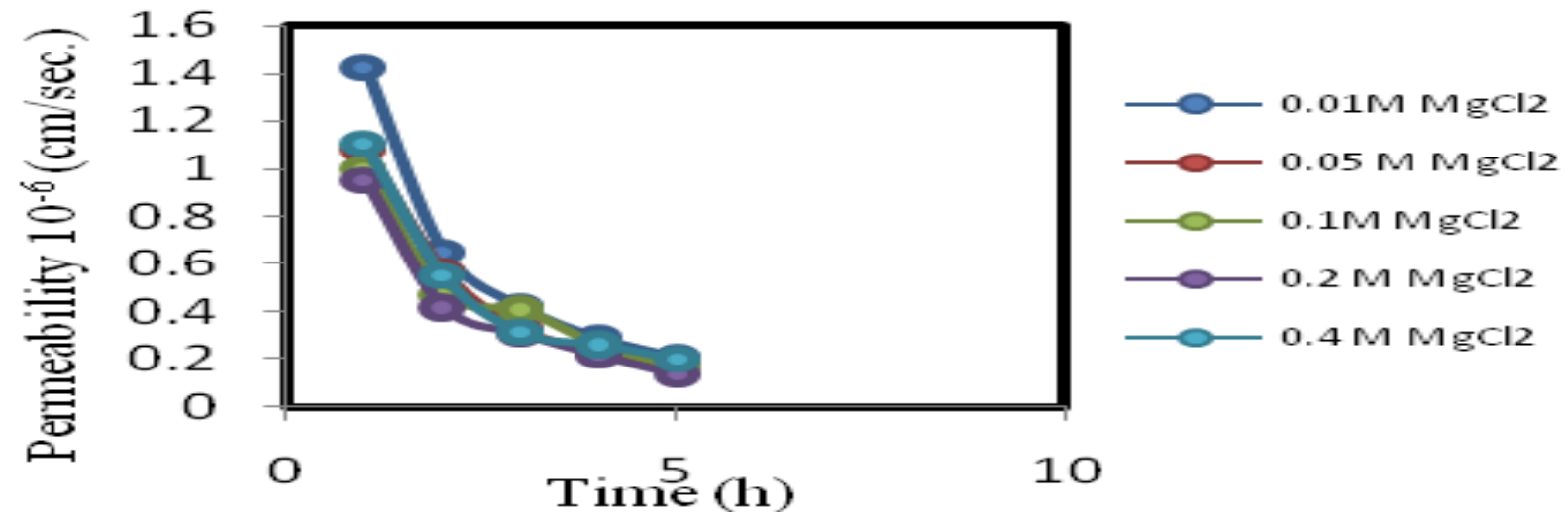

Fig.-10b: Dependence of Permeability in Cellulose Acetate/Chitosan Membrane with Time in Various Concentrations of $\mathrm{MgCl}_{2}$ Solution.

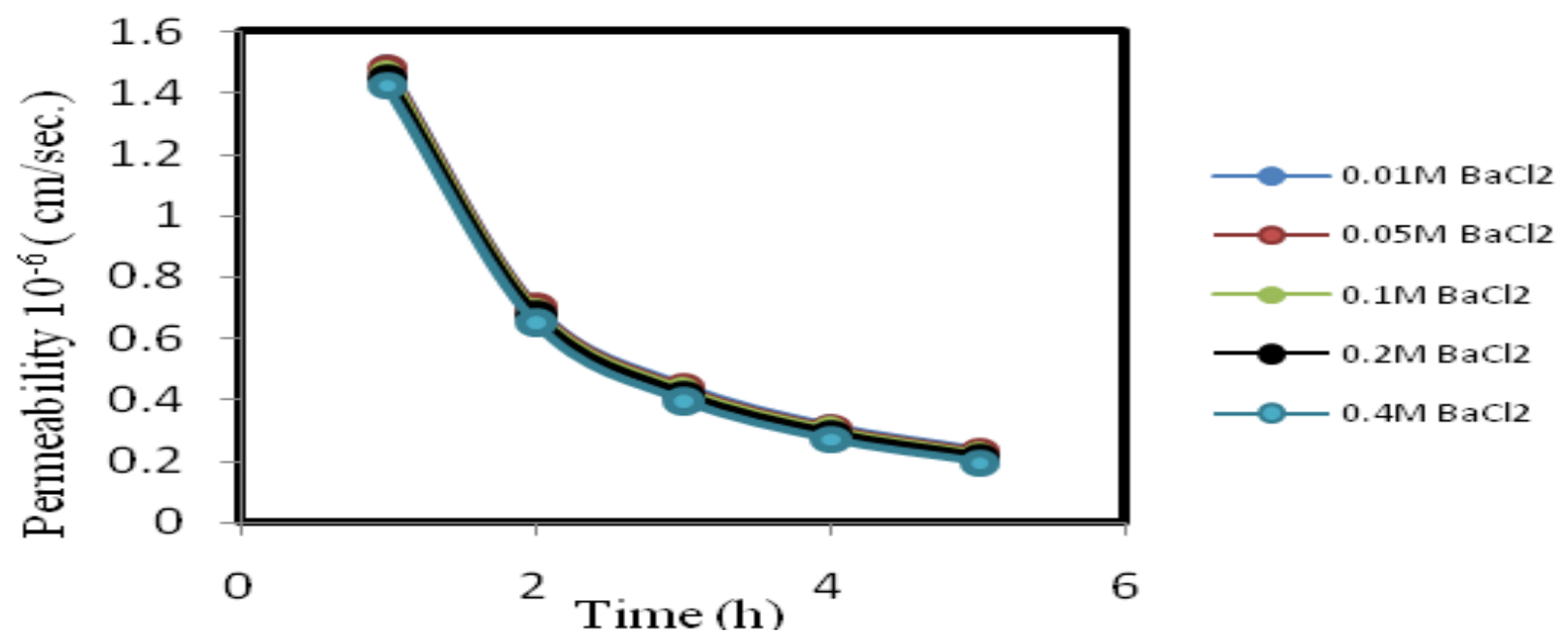

Fig.-10c: Dependence of Permeability in Cellulose Acetate /Chitosan Membrane with Time in Various Concentrations of $\mathrm{BaCl}_{2}$ Solution 
RASĀYAN J. Chem.

Vol. 12 | No. 1 |73-84| January - March | 2019

The unit of membrane flow $\left(\mathrm{cm}^{3} / \mathrm{sec}\right.$.). Flow is the concentration difference process which generates permeate and retentat. The flow of the ions decreases with increasing the time, which shows in Fig.-11a, $11 \mathrm{~b}$, and 11c. It shows that the transfer of ions decreases with the time, this is due to the concentration of the solution decreases with time.
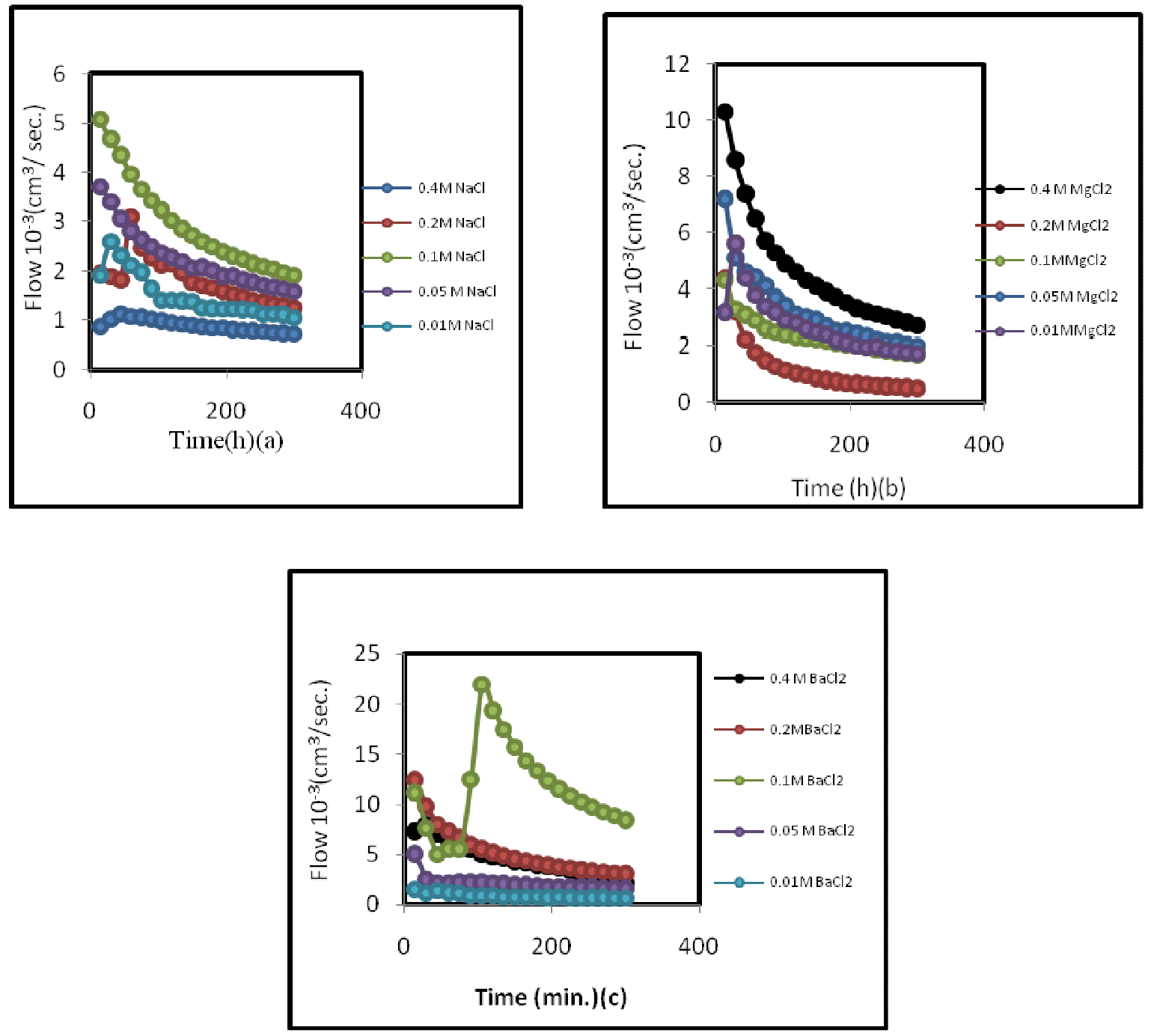

Fig.-11a, b and c: Time-dependent Flow of the Membrane Systems

\section{Permeability}

Permeability is material flow per unit area through the membrane. This is calculated by the following relation:

$$
\mathrm{P}=\frac{\text { Flow }}{\text { Area }}
$$

The unit of permeability is $\mathrm{cm} / \mathrm{sec}$. The permeability of ions decreases with increase the time, which shows in Fig.-12a, b and c.

Flux- Flux is the permeability time's concentration difference. This is calculated by the following relation:

$$
\mathrm{J}_{\mathrm{s}}=P \times \Delta C
$$


RASĀYAN J. Chem.

Vol. 12 | No. 1 |73 - 84| January - March | 2019
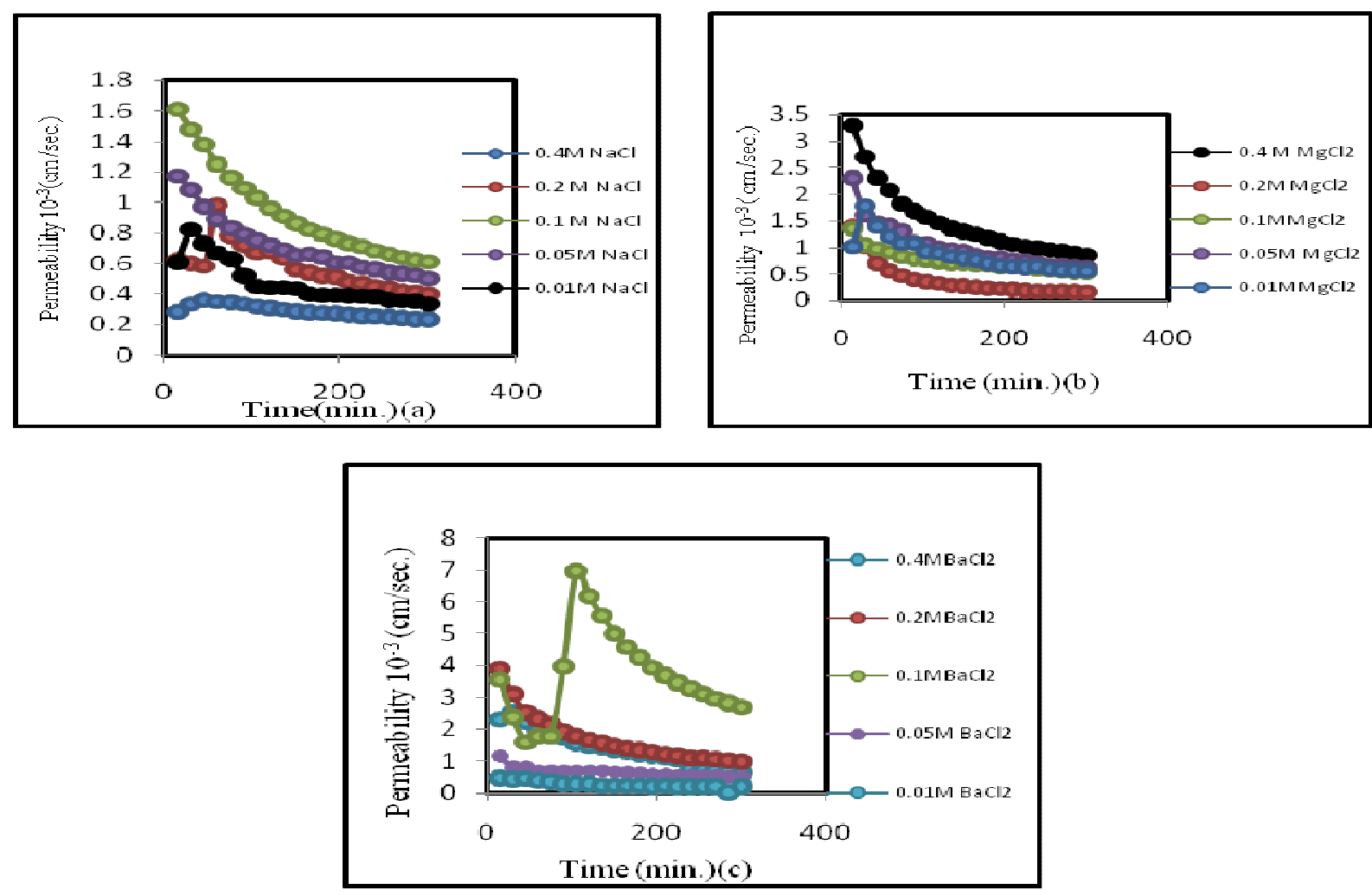

Fig.-12a, b and c: Time-dependent on Membrane Permeability of Different Systems.
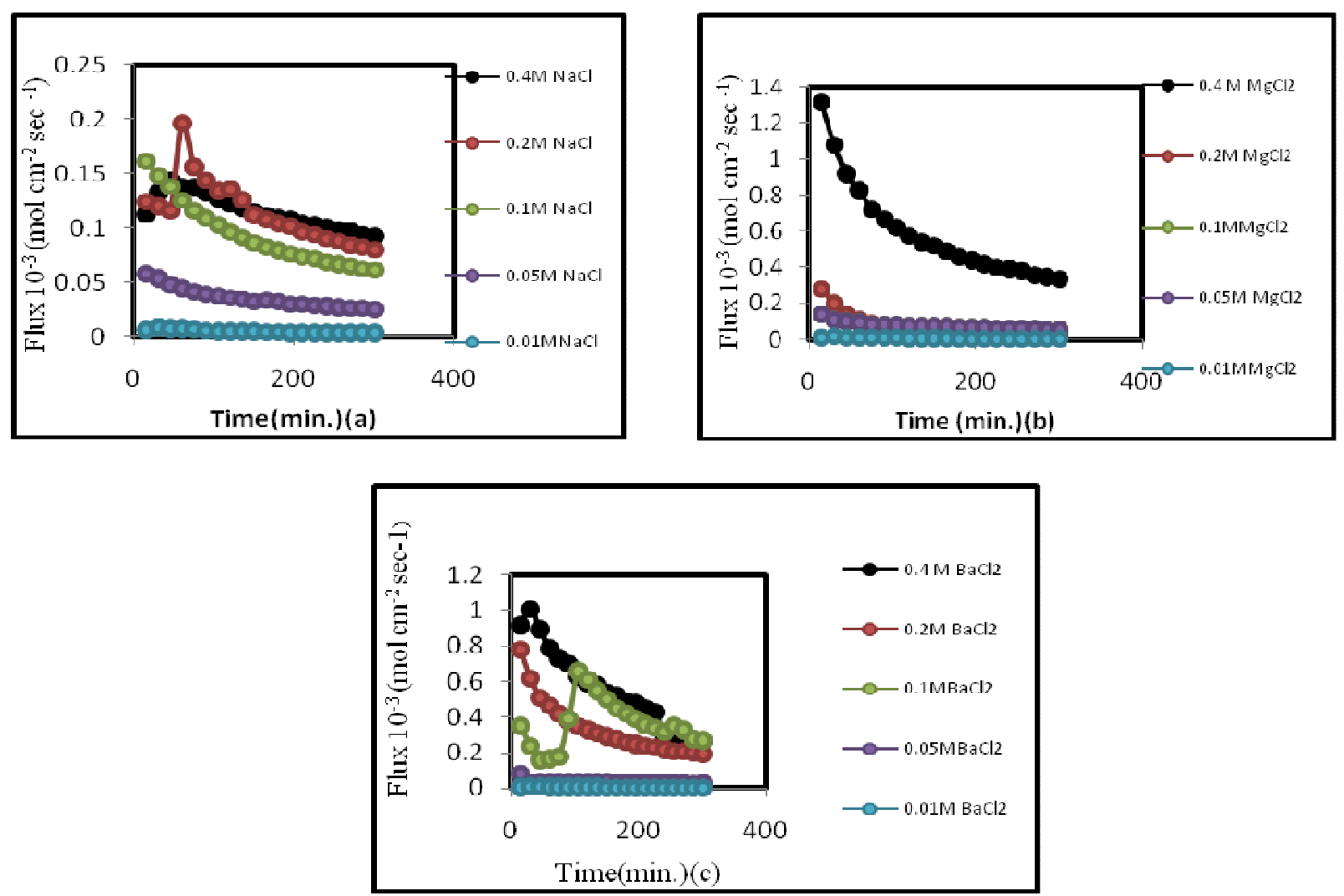

Fig.-13a, b and c: Time-dependent Flux of Membrane Systems. 
The unit of flux is mol cm$~^{-2} \mathrm{sec}^{-1}$. The flux of ions decreases with increase of the time, which is shown in Fig.-13a, b and c.

There is decrease in water uptake as salt concentration increases, and permeability of the salt decreases with increasing the salt concentration. The conductance of solution through membrane increases with increases of time. It shows that ions are easily transported through the membrane and indicating porous character of the membrane. Flow, flux and permeability of the membrane decrease with the increase of time. Permeability is almost directly proportional to the membrane porosity.

In concentrate solutions of $\mathrm{NaCl}, \mathrm{MgCl}_{2}$ and $\mathrm{BaCl}_{2}$ flow, permeability and flux decrease steadily with time while in dilute solution flow and permeability decreases rapidly with time .This indicates that in dilute solution fewer ions are available for permeation through the membrane.

\section{CONCLUSION}

The present membrane possesses hydrophilic character. This can be expected on the basis of membrane water content. The trend of water content variation in the membrane phase has been shown differently in aqueous and saline environments. The rate of conductance variation is always positive in each case. On the basis of TGA, it appears that in the membrane texture different type of water molecules are associated.SEM photographs show less heterogeneity exists in the membrane system.

\section{ACKNOWLEDGMENT}

We are thankful to Head, Chemistry Department of D.D.U. Gorakhpur University Gorakhpur for providing laboratory facilities and U.G.C. JRF fellowship for financial support.

\section{REFERENCES}

1. J.A.L. Ramrez, M.D. Oviedo and J.M. Alonso, Desalination, 191, 137(2006), DOI: 10.1016/j desal.2005.08.013.

2. V.A. Pham, J.P. Santerre, T. Matsuura and R.M. Narbaitz, J Appl Polym Sci., 73, 1363(1999), DOI: 10.1002/(SICI)1097-4628(19990822)73:8< 1363 : :AID-APP 3.0.CO; 2-p.

3. H. Yuan, B. Yu, H. Cong, Q. Peng, R. Yang, S. Yang, Z. Yang, Y. Luo, T. Xu, H. Zhang, and Z Li, Rev. Adv. Mater. Sci., 44, 207(2016).

4. H.A. Tsai, H.C. Chen, K.R. Lee, and J.Y. Lai, Desalination, 193, 129(2006), DOI: 10.1016/j.desal.2005.04.140.

5. A. EL-Gendi, A. Deratani, S.A. Ahmed and S.S. Ali, Egypt. J. of Pet., 23, 169(2014), DOI: 10.1016/j.ejpe.2014.05.003.

6. S. Jana, M.K. Purkait and K. Mohanty, Desalin Water Treat., 37, 321(2012), DOI: 10.1080/19443994.2012.661574.

7. R. Huang, G. Chen, M. Sun and C. Gao, Sep. Purif. Technol., 58, 393(2008).

8. D. Raafat and H.G. Sahl, Microb Biotechnol., 2,186 (2009), DOI: 10.1111/j1751-7915.2008.00080.x.

9. P.K. Dutta, J. Dutta and V.S. Tripathi, J. of Sci. Ind. Res, 63, 20 (2004).

10. E. Szymanska and K. Winnicka, Review Mar. Drug, 13, 1819 (2015), DOI: 10.1088/md13041819 .

11. Y.M. Yusof, M.F. Shukur, H.A. Illias and M.F.Z Kadir, Phys. Scr., 89, 035701(2014), DOI: 10.1088/003-8949/89/03/035701.

12. P.S. Ghose, T. Matsuura, A.F. Ismail and N. Hilal, Desalination, 391, 43(2016), DOI: 10.1016/j.desal.2015.12.016.

13. K. Singh, and A.K. Tiwari, J. Colloid Interf Sci., 210, 241(1999).

14. A.K. Tiwari, and S. Ahmad, J. Colloid Interf Sci., 298, 274(2006).

15. G.M. Geise, D.R. Paul and B.D. Freemann, Prog. Polym. Sci., 39, 1(2014), DOI: 10.1016/j.progpolymsci.2013.07.001.

[RJC-3093/2018] 